\title{
Taking Institutions Seriously: Using the IAD Framework to Analyze Fisheries Policy
}

\author{
MARK T. IMPERIAL \\ Department of Political Science, University of North Carolina at \\ Wilmington, Wilmington, North Carolina, USA
}

TRACY YANDLE

Department of Environmental Studies, Emory University, Atlanta, Georgia, USA

\begin{abstract}
We argue that the fisheries management literature often does a poor job of analyzing issues related to institutional design and performance. The article begins by examining four competing institutional arrangements used to manage fisheries: bureaucracy, markets, community, and comanagement. The differences are used to highlight the importance of understanding critical issues related to institutional analysis. The article then examines some of the common problems or pitfalls that analysts fall victim to when examining institutional design and performance. We conclude by summarizing the Institutional Analysis and Development (IAD) framework, one approach to institutional analysis that avoids these common pitfalls.
\end{abstract}

Keywords comanagement, community-based management, fisheries management, individual transferable quotas, institutional analysis, institutions, policy analysis, market-based regulation

Many of the world's major fisheries are in poor shape, particularly the fisheries highly valued for migratory species and groundfish (Myers and Worm 2003). Some attribute these problems to bad science or the failure to account for the interactions in large marine ecosystems. Others argue that fisheries management fails to change incentive structures, promotes inefficient fishing practices, or is inconsistent with community values. Fisheries management also presents a classic collective action problem (Olson 1965).

Most fisheries management programs in the United States and abroad rely on one of the following types of institutional design: (1) the "leviathan" or centralized bureaucratic arrangement based on government regulation; (2) marketbased arrangements that allocate total allowable catch (TAC) using individual

Received 24 March 2003; accepted 10 November 2004.

This material is based in part on work supported by the National Science Foundation (NSF) under grant 9905271 and Emory University's University Research Committee grant 2002067. Any opinions, findings, conclusions, or recommendations expressed in this material are those of the author(s) and do not necessarily reflect the views of the NSF.

Address correspondence to Mark T. Imperial, Department of Political Science, University of North Carolina at Wilmington, 601 South College Road, Wilmington, NC 284035607, USA. E-mail: imperialm@uncw.edu 
transferable quotas (ITQs); and (3) community-based arrangements that rely on self-regulation of fisheries by communities and user groups (Charles 1992). Comanagement has now emerged as a fourth hybrid arrangement that relies on shared management between government agencies and user groups (Yandle 2003).

All four institutional arrangements have their supporters and critics. Unfortunately, many analysts and decision makers ignore institutional arrangements completely or treat them in overly simplified terms that fail to appreciate their complexity. By "analysts", we are referring to the broad range of individuals who perform policy analysis. That is, the provision of policy-relevant information and advice to decision makers. This includes not only analysts employed by government agencies but also those who work in other places such as academia, industry, think tanks, or conservation organizations.

We argue that a broad-based approach to policy analysis that considers institutional design and performance is needed in order to craft effective fisheries management programs. Institutions are "enduring regularities of human action in situations structured by rules, norms, and shared strategies, as well as by the physical world. The rules, norms, and shared strategies are constituted and reconstituted by human interaction in frequently occurring or repetitive situations" (Crawford and Ostrom 1995, 582). Institutions include families, churches, local governments, government agencies, and most organizations, because they are defined by rules, norms, and shared strategies (Ostrom, Schroeder, and Wynne 1993, 6). Institutions promote positive outcomes by helping actors resolve "social dilemmas" produced when individually rational actions aggregate to produce socially irrational outcomes.

What differentiates institutional analysis from other forms of organizational analysis is the focus on rules. Rules are prescriptions that forbid, permit, or require some action or outcome and the sanctions authorized if the rules are not followed (Crawford and Ostrom 1995). Rules can be formal (e.g., laws, policies, regulations, etc.) or informal (e.g., social norms). The stability of rule-ordered interactions depends on a shared understanding of rules (Ostrom, Gardner, and Walker 1994, 40). This requires building trust by monitoring and enforcing rules. Enforcement includes formal (e.g., civil or criminal penalties) or informal (e.g., a verbal comments) sanctions.

Accordingly, institutional analysis examines problems that individuals (or organizations) face and how rules address these problems. In the context of fisheries management, it focuses on such things as the organization of the fishery (e.g., location, community characteristics, industry structure, etc.), who makes decisions, how decisions are made, the rules used to allocate and distribute resources, rules governing fisher behavior, and rule enforcement.

We begin the article with a brief discussion of the four types of institutional arrangements used to manage fisheries in order to identify their characteristics and illustrate the importance of institutional design and performance. We then examine some of the problems or pitfalls that analysts fall victim to when analyzing institutional arrangements. We conclude by describing one approach to institutional analysis that helps avoid these pitfalls, the Institutional Analysis and Development (IAD) framework developed by Elinor Ostrom (1986; 1990; 1999) and her colleagues (e.g., Ostrom et al. 1993; 1994; Kiser and Ostrom 1982). 


\section{Competing Forms of Institutional Design Used to Manage Fisheries}

Fisheries management programs are often based on three types of institutional arrangements: (1) bureaucracy-based, (2) market-based, or (3) community-based (Charles 1992) ${ }^{1}$. Comanagement has now emerged as a fourth arrangement (Yandle 2003; 2004). Common characteristics of each arrangement are summarized in Table 1.

\section{Bureaucracy-Based Forms of Institutional Design}

A common assumption is that an external leviathan is necessary to prevent the "tragedy of the commons." Thus, institutional arrangements based on centralized government control are commonly found, particularly in developed countries (Larkin 1977). We view this institutional arrangement as a default position. Analysts do not write about the need for centralized state control over fisheries in the United States because a well-developed regulatory system exists. Rather, analysts spend time examining the development and implementation of various fisheries management plans and regulations (e.g., Hennessey and Healey 2000). Since it occupies the default position, bureaucracy-based arrangements are widely criticized by those favoring alternative arrangements (e.g., Leal 2002).

In bureaucracy-based arrangements, property rights to fish are held by government on behalf of the public and the focus is on developing regulations that maintain fish stocks at sustainable levels. However, other social goals may be embedded in these programs. For example, the Canadian government uses fisheries policy to promote employment, while in the United States there are numerous requirements for fisheries managers to consider economic and social factors when making decisions.

Determining the total allowable catch (TAC) plays an important role in bureaucracy-based arrangements because this information is used to control the effort of a fleet by adopting rules that limit entry, imposing size limits, creating seasons, restricting gear or effort, or imposing closures. Presumably, where there is some stability in these rules, it improves accountability, lowers administrative costs, and improves equity, since the rules often apply to all fishers or some subgroup. This may preserve small fishers and is consistent with the view of fishing as an individualistic enterprise. However, rules can also be crafted that restrict entry or push out small fishers (e.g., high license or gear costs).

The process of developing fishery management plans is easily politicized and subject to capture by fishers, industry, or even conservation groups (Smith et al. 2003). Conflicts among competing stakeholders can make policy change costly, time-consuming, and increase information costs. Consequently, the system's ability to rapidly adapt to stock fluctuations, technologic advances, or changing social, political, and economic conditions may be reduced. Conversely, problems occur in any institutional arrangement when the system is "chaotic" and rules are changed frequently in response to political pressure before fishers adapt or decisionmakers can tell if rules are working.

Bureaucracy-based arrangements can also be inefficient. Rules can encourage overcapitalization of a fishery. Rules may increase the effort required to harvest the same quantity of fish. High discards result in additional wasted effort and undocumented stock loss. Rules can create derbies that reduce ex-vessel prices for fishers. 


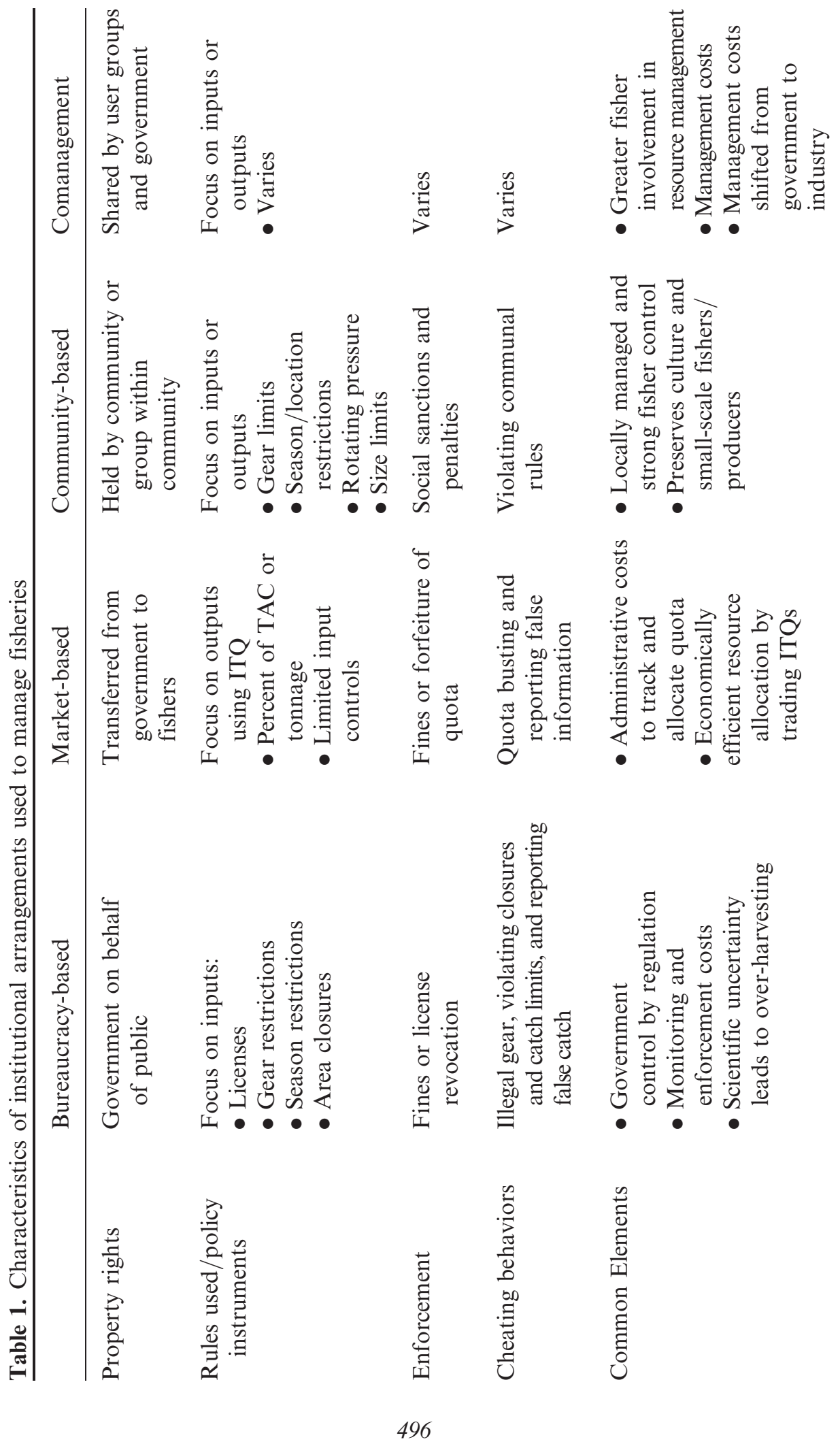



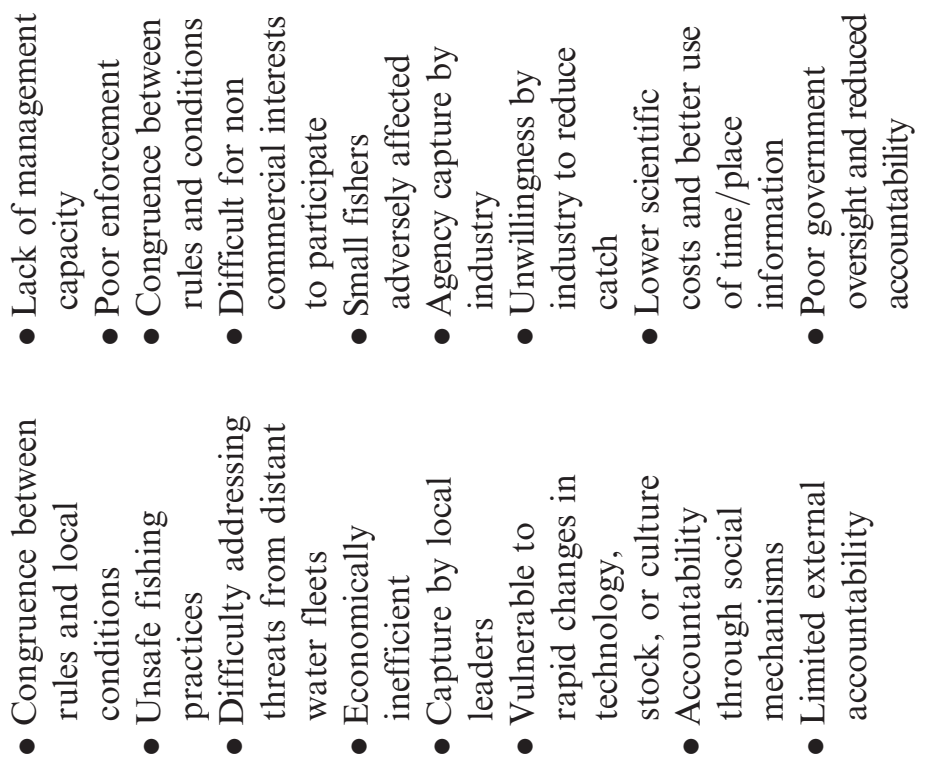

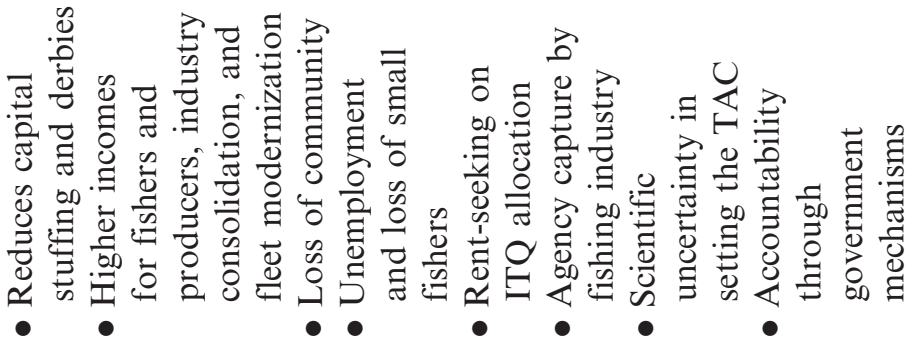

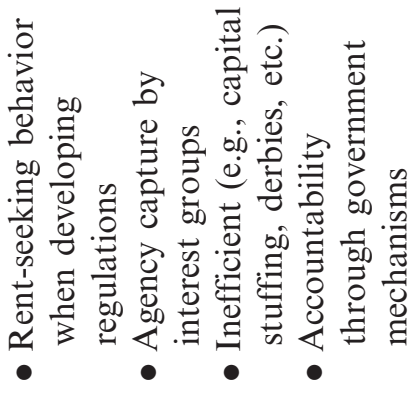


Rules also create incentives to engage in various forms of cheating behavior such as using illegal gear, violating size limits, fishing during closed seasons or in closed areas, violating catch limitations, and underreporting catch (Halliday and Pinhorn 1997). Thus, there can be high enforcement costs and the danger of driving out law-abiding fishers when they cannot compete with lawbreakers.

\section{Market-Based Forms of Institutional Design}

During the 1980s, a number of countries began experimenting with market-based institutional arrangements (Squires, Kirkley, and Tisdell 1995). While bureaucracybased arrangements focus on regulating inputs, market-based arrangements emphasize outputs by maintaining sustainable stocks using a trading system that allocates property rights from government to vessel owners or fishers using a tradable permit referred to as individual tradable/transferable quota (ITQ).

Economic, legal, and policy scholars often differ in their conceptions of property rights (Cole and Grossman 2002). Consequently, there is some debate as to whether ITQ systems constitute a transfer of property rights. When viewed from the perspective of institutional analysis, analysts are concerned with how rights, duties, power, and authority are distributed through the development of rules. In market-based arrangements, regulatory authorities determine the TAC and allocate it to vessel owners or fishers, usually in the form of tonnage or percentage of the TAC. The owners of ITQs are then free to trade their permits (i.e., rights to catch fish) in a manner that (theoretically) produces a Pareto efficient resource distribution (Kneese and Schultze 1975). From the perspective of institutional analysis, a property right to catch these fish has transferred from government to the holder of an ITQ. We do not consider other financial mechanisms here, such as tax expenditures or user fees, that create incentives to change behavior but do not transfer property rights or rely on the market to allocate resources.

An important characteristic of market-based arrangements is the emphasis on economic efficiency and higher incomes for fishers and the industry (Clark 1993). It promotes industry modernization (Clark 1993). It can create a corporatist culture within the industry. It also eliminates some types of economic inefficiency (e.g., derbies, overcapitalization, etc.) associated with bureaucracy-based arrangements (Grafton 1996).

Another characteristic is the limits on TAC that may not exist in bureaucracybased arrangements (Dewees 1989). This can help fishers and processors make better operational decisions and investments. It is adaptable because the TAC is often set on a yearly or seasonal basis. Accordingly, adjustments can be made to account for dramatic changes in stocks or other unforeseen circumstances (Squires et al. 1995). To the extent that decision making is transparent, it enjoys public accountability.

However, industry consolidation and loss of small fishers can have negative implications (Copes 1996). Unemployment can result, which can become problematic, depending on the skills of displaced workers and the health of the local economy (Squires et al. 1995). Corporate ownership can transfer wealth out of local communities, lesson the sense of community, and damage local institutions (Ostrom 1990). Equity issues also occur when some fishers get more TAC or new fishers have difficulty entering the fishery (Palsson and Helgason 1996).

Market-based arrangements also have high information costs because they require accurate stock assessments (Mace 1993). If the TAC is set incorrectly, a 
fishery can be quickly decimated, perhaps before the error is corrected. Setting and allocating TAC is a political process and thus subject to agency capture and rentseeking behavior. Setting a TAC can be problematic when decision makers are confronted with scientific uncertainty. The process can also be distorted if fishers increase catch in an effort to "fish for quota" in the years leading up to the introduction of an ITQ system. Moreover, while ITQ systems eliminate some cheating behavior, they don't reduce incentives to cheat. Instead, it introduces different cheating behavior by creating incentives for fishers to high-grade their catch by sorting fish at sea and throwing back smaller or less valuable fish to maximize their revenue per ton of quota. Other types of cheating include false catch reporting, dumping by-catch, and diverting catch to ports outside the monitoring system (Copes 1996).

\section{Community-Based Forms of Institutional Design}

Community-based arrangements are more eclectic than their bureaucratic and market-based counterparts and go by various names such as community-based management, self-regulation, folk management, and delegated management authority. In this institutional arrangement, the community (or group within the community) holds property rights to fish and the emphasis is on encouraging fishing communities to develop rules to regulate themselves or to maintain existing self-governance systems such that social norms, rules, and sanctions are used to allocate fishing rights or govern fisher behavior (Ostrom 1990). Rules take a variety of forms, including gear limits, restrictions on effort or seasons, and rotating positions on fishing grounds. Social sanctions are the primary enforcement tool, although monetary or material sanctions may be used (Ostrom 1990).

Different goals and values are embedded in community-based arrangements. These include resource user control (rather than centralized government control), the preservation of community culture, internal accountability, and preservation of small fishers and communities (McCay and Jentoft 1996). However, unlike bureaucracy- and market-based arrangements, there are few critics, and research has a tendency to "romance the commons" by focusing on "success stories" that examine small fishing communities in developing countries. As a result, analysts interested in large-scale commercial fisheries may not view it as a viable institutional arrangement (Leal 2002).

One problem is capture by local leaders and the resulting social inequalities (Davis and Bailey 1996). There is also conflicting evidence on whether norms change rapidly enough to respond to changing ecosystems or incentive structuresparticularly when the changes are driven by outside forces (Rose 2002). The absence of central state control can also lead to a lack of public accountability and even illegal behavior. Rule enforcement and the "lobster gangs" of Maine are an example (Acheson 1988). In some cases, the rules developed to govern fishers in communitybased arrangements are inefficient and rely on labor-intensive practices that sometimes produce unsafe working conditions. They can also lead to dangerous fishing practices (e.g., use of poisons and explosives). Community-based arrangements may also have problems controlling distant water fishing fleets.

\section{Comanagement Forms of Institutional Design}

Comanagement has now emerged as a fourth institutional arrangement that is used in developing and developed nations (Yandle 2003). Comanagement is a hybrid 
institutional arrangement that emphasizes sharing responsibility for fisheries management between government and user groups to manage a fishery in order to reduce costs to government and improve decision making. Fisher involvement improves the quality of the time and place information used to craft management systems by tapping local knowledge. It also results in a greater congruence between local conditions and the institutional arrangement, thus reducing transaction costs.

A key characteristic of comanagement is the distribution of property rights. If property rights are viewed as a bundle of rights and responsibilities, then comanagement splits the property rights bundle between users and government. The distribution of property rights is important because resource users must, at a minimum, have access, withdrawal, and management rights to have sufficient incentive to manage resources over the long-term (Ostrom and Schlager 1996).

Each comanagement arrangement is somewhat unique and uses a combination of policy instruments employed by the aforementioned arrangements that is tailored to fit local conditions (McCay 1993). Accordingly, enforcement ranges from government penalties to social sanctions and it is problematic when fishers are unwilling to sanction fellow fishers. Cheating behavior still exists and tends to reflect the combination of policy instruments used. These arrangements are subject to capture when industry is unwilling to reduce catch when necessary. It can be difficult for noncommercial interests or small fishers to participate in these systems (Yandle 2003). Moreover, while comanagement may reduce costs to government, user groups must have the financial, technical, and administrative capacity to perform their management responsibilities.

\section{Taking Institution Design and Performance Seriously}

The analysis of these institutional arrangements demonstrates the importance of understanding institutional design and performance. Since the same policy objective can be achieved using different institutional arrangements, an important question for analysts to consider is the comparative advantage of an institutional arrangement, given contextual factors and competing goals and values of decision makers. Unfortunately, some analysts base their choices solely on the technical properties of an institutional arrangement. For example, an analyst or decision maker may choose to use an ITQ system because it has the promise of increasing economic efficiency. However, institutional arrangements are seldom value neutral; nor are they distributionally equal. Returning to the previous example, it would be unfortunate if decision makers were unaware that industry consolidation and the loss of small fishers are potential by-products of their effort to increase efficiency by using ITQ systems.

It is important to recognize that institutional arrangements have differential effects on the positions and power of various policy actors because they alter the relative importance of the resources they posses (Majone 1989, 117). Furthermore, the performance of policy instruments often depends less on their formal properties than on the political and administrative context within which they operate. Institutional arrangements can shape policy results and should be considered when analyzing policy choices (Majone 1989, 118).

\section{Common Pitfalls in Conducting Institutional Analysis}

The product of policy analysis is policy-relevant information and advice to decision makers. In fisheries, this advice often centers on the nature of the rules used 
to alter fisher behavior and maintain sustainable fish stocks. However, our discussion demonstrates that rules can be delivered through different institutional arrangements. Accordingly, policy analysis should provide decision makers with information needed to make informed choices about institutional design. Unfortunately, analysts often fail to adequately consider the complexity and range of factors influencing institutional design and performance. Rather than highlight the deficiencies of particular studies or programs, it is more constructive to review the common pitfalls confronting analysts.

Bias for Case Studies. Much of the fisheries literature is case driven and reflects what Bozeman (1993) calls wisdom literature - studies that contribute to our understanding not by gathering empirical data or providing frameworks for the analysis of empirical data but by synthesizing existing literature, reporting impressions, systematically reporting personal experiences, or relying on other approaches that can be systematic but are not theoretical (Bozeman 1993, 31). By way of contrast, theoryseeking literature does one or more of the following: (1) provides explicit and testable hypotheses; (2) develops analytical devices for explanation; (3) aspires to generalization; (4) assumes that aggregation is meaningful in analysis; (5) provides some degree of analytical separation between fact and value; (6) assumes that theoretical progress is no illusion but real and demonstrable (Bozeman 1993, 31). Accordingly, it is important to move beyond single-case studies and to perform comparative analysis whenever possible (e.g., Ostrom 1990).

Faulty Lesson Drawing. Many studies suffer from what Rose (1993) calls faulty lesson drawing. The analyst assumes that a particular institutional arrangement will work equally well in other settings without fully considering how contextual factors influence its performance or transferability. For example, there can be problems when ITQ systems are implemented without proper administrative or scientific support or when they fail to recognize conflicts with existing community-based regimes (Ostrom 1990). If analysts want to provide sound advice to decision makers, they must identify contextual factors that influence institutional performance and determine whether these factors enhance or impede transferability (Rose 1993).

Cognitive Bolstering and Faulty Logic. Sometimes analysts magnify the value of a chosen action while denigrating the value of rejected alternatives. When analysts fall victim to cognitive bolstering, they unconsciously abandon critical evaluation and exaggerate favorable aspects of an institutional arrangement while minimizing or failing to consider unfavorable consequences. This becomes problematic when critical evaluation is narrowed to what is needed to justify a favored course of action. On a conscious level, the analyst may simply use faulty logic to justify an institutional choice by dismissing other possibilities after reciting a "long parade of horribles" associated with alternative choices (Komesar 1994, 6). The problem is that "In a world of institutional alternatives that are both complex and imperfect, institutional choice by implication, simple intuition, or even long lists of imperfections is deeply inadequate" (Komesar 1994, 6). Accordingly, it is important for analysts to carefully evaluate the merits of alternative institutional arrangements.

Single Institutionalism. Another potentially serious problem is what Komesar $(1994,6)$ calls "single institutionalism." The analyst examines the variation in performance of only one type of institution, thereby ignoring the possibility that other arrangements may achieve similar objectives at equal or lesser cost. Thus, analysts 
who conduct a limited analysis can draw inappropriate conclusions about which institutional arrangement is likely to work best in a particular setting (Komesar 1994, 6).

Ignoring the Full Range of Transaction Costs. Another pitfall is performing a truncated analysis that ignores the full range of transaction costs associated with fisheries management programs. Transaction costs are resources expended as a result of imperfect information (Williamson 1985). Transaction costs tend to increase as the number of bargaining partners and routine interactions increases because it becomes more difficult for actors to reach agreement and discern what (if any) alternatives will satisfy participants. Thus, as jurisdictional complexity increases and the actors' interests become increasingly heterogeneous, transaction costs rise (Imperial 1999). Transaction costs can also increase when asymmetries of information and power exist because they increase information costs or provide opportunities for actors to engage in strategic behavior (e.g., free riding, rent seeking, shirking, corruption, turf guarding, etc.) (Ostrom et al. 1993). Accordingly, organizations in which individuals or groups fail to cooperate and trust each other will be less efficient than those that do (Williamson 1985).

Using Narrow Criteria to Assess Institutional Performance. Analysts must consider not only the policy but also the institutional arrangement used to implement the policy and the context in which it is implemented. Given this complexity, it is unlikely that a single criterion such as economic efficiency will reveal the full range of benefits or costs associated with an institutional arrangement. Consequently, analysts are advised to use multiple measures to provide decision makers with information needed to make informed choices about the institutional arrangement used to implement policy (Majone 1989, 169).

Failure to Use Conceptual Frameworks. Institutional arrangements can be extremely complex. To avoid getting lost in details, analysts need to be disciplined and focus on a manageable set of key variables such as (1) actual or potential actors; (2) the resources available under different institutional arrangements; (3) the amount and quality of information, skills, and expertise available to various actors; and (4) factors and constraints such as existing policies, societal values, ideologies, public opinion, and cognitive paradigms (Majone 1989, 100). In this regard, institutional analysis is similar to theory-seeking literature in that it should use conceptual or theoretical frameworks to encourage systematic analysis of data and strive toward the aggregation of knowledge and the generalization of research findings.

\section{Using the IAD Framework to Improve Institutional Analysis}

The Institutional Analysis and Development (IAD) framework is one of many approaches to conducting institutional analysis (Ostrom 1986; 1990; 1999; Ostrom et al. 1993; 1994; Kiser and Ostrom 1982). Our objective is not to argue that the IAD framework is the "best" approach for analyzing fisheries management institutions. However, it has proved useful in understanding a wide variety of institutional arrangements in both developed and developing countries. It also avoids many of the common pitfalls noted in the previous section. It emphasizes the careful consideration of contextual factors. It draws attention to the full range of transaction costs. It contains no normative biases and does not presume a priori that one type of 
institutional arrangement is preferred to another. It also uses a variety of criteria to assess institutional performance. The following subsections describe the framework's major elements to in order to illustrate how it might be used to analyze fisheries management institutions.

\section{Examining the Contextual Setting}

The analyst must first identify what Ostrom (1990) calls the action arena. This typically includes the fishery and the community affected by the rules governing a fishery. The community may be a small village or port or extend to a larger region (e.g., New England ground fishery). The full set of participants might include fishers, captains, crews, vessel owners, buyers, processors, distributors, regulators, and the corresponding community, including those individuals and organizations that provide services to these actors. The IAD framework suggests focusing attention on three sets of contextual factors (Ostrom 1999).

Physical Setting. To be effective, the rules governing a resource must be compatible with the underlying physical setting and the nature of the resource being managed (Ostrom et al. 1994, 44). Since there is often considerable variation in physical settings, resource, and resource management problems, a search for the best rule for all situations is likely to be doomed to failure (Ostrom et al. 1994, 237). For example, a community-based arrangement that is effective at managing nearshore fisheries may not be effective in monitoring offshore fisheries.

Attributes of the Community. This includes norms of behavior, level of common understanding, homogeneity of preferences, and the distribution of resources. It also includes relevant political and socioeconomic factors. The term "culture" is often applied to this bundle of variables (Ostrom et al. 1994, 45). Cultural factors often play a role in fisheries conflicts and influence the development and administration of rules governing a fishery (Charles 1992; Ostrom 1990). For example, an ITQ system may work well in a fishery heavily influenced by corporate ownership. However, a comparable fishery with a culture based on individual vessel ownership may resist market-based systems.

Existing Institutional Setting. Analysts should recognize that institutional change tends to be incremental and path dependent rather than totally reconstructive or destructive (Imperial 1999; Ostrom 1990). Since the process is incremental and sequential, early successes are needed before participants are willing to make larger investments. When viewed over time, these changes allow the participants to improve the capacity of fishery management institutions. The process tends to be path dependent because each institutional change transforms the structure of incentives within which future decisions are made. Thus, analysts should consider how a policy change enhances or constrains future policy options. Moreover, the longer a rule system stays in place and the more sophisticated and complex it becomes, the more likely it is that decision makers will encounter difficulty when trying to make changes.

\section{Examining Transaction Costs}

The IAD framework suggests that analysts examine three types of transaction costs associated with developing and implementing fisheries policy: (1) information costs; (2) coordination costs; and, (3) strategic costs (Ostrom et al. 1993). 
Information Costs. Information costs are those associated with searching for and organizing information and the errors resulting from an ineffective blend of scientific and time and place information (Ostrom et al. 1993, 120). Scientific information is "acquired by individuals through education and/or experience about the regularities of relationships among key variables rather than the particular state of those variables in a specific context" (Ostrom et al. 1993, 50). Time and place information refers to the knowledge "acquired by individuals who know the nature of a particular physical and social setting" (Ostrom et al. 1993, 50). Effective fisheries management requires an effective blend of both scientific and time and place information. Fisheries managers need to understand the species and its population dynamics. They also need accurate information about breeding populations and changing local conditions.

Coordination Costs. Coordination costs are those invested in negotiating, monitoring, and enforcing agreements (Ostrom et al. 1993, 120). This includes the costs to develop policy proposals and the corresponding costs associated with negotiation, bargaining, and public comment necessary to obtain approvals by decisionmakers. Accordingly, to the extent that the transaction costs associated with interagency meetings and negotiations are high, agencies or fishers may be reluctant to participate in decision making or may do so on an informal or sporadic basis. Alternatively, in a community-based system, coordination costs are associated with the social processes used to develop shared norms and acceptable rules of behavior, which often take a long time and require considerable effort (Ostrom 1990, 90). Enforcement is a coordination cost in all four institutional arrangements due to incentives for fishers to cheat and the physical environment can make it difficult and expensive to catch cheaters. For example, "one study showed that in the Georges Bank fishery, regulations were frequently violated by a quarter to a half of all fishers" (Halliday and Pinhorn 1997, 103).

Strategic Costs. Strategic costs result from asymmetries in information, power, or other resources such that some obtain benefits at the expense of others. Common strategic costs include free riding, rent seeking, corruption, collusion, and turf guarding. As a result, agencies and fishers may be reluctant to enter into cooperative relationships when there is suspicion that others will engage in strategic behavior. Rent seeking may be the most common strategic behavior observed in all four institutional arrangements. Fishers may try to modify the rules (e.g., regulations, TAC, ITQ, etc.) so they can extract more rent in the form of income or revenue. This can result in short-term financial gains for fishers at the long-term expense of healthy stocks. It is also possible for administrative agencies to be "captured" by fishers, some component of industry, or even environmental groups. For example, some argue that fisher and industry capture of regional fishery management councils in the United States has produced an inefficient industry with policies that hastened the collapse of many species (Wilen 1995).

Interestingly, while rent seeking is usually viewed in negative terms, communitybased arrangements often view comparable behavior as community leadership. However, community elites may engage in rent-seeking behavior that is costly to the community or society. As Davis and Bailey $(1996,262)$ point out, "local elites are quite capable of capturing the process and benefits of whatever technology or policy changes that come along." 


\section{Assessing Overall Institutional Performance}

The IAD framework relies on four interrelated criteria to assess the overall performance of institutional arrangements: (1) efficiency, (2) equity, (3) accountability, and (4) adaptability (Ostrom et al. 1993). It is also important to understand the relationship between institutional performance and policy outcomes.

Efficiency. Efficiency can be viewed in many ways. Economic efficiency focuses on the magnitude of the change in the flow of net benefits associated with an allocation or reallocation of resources. When the economy works efficiently, no reallocation of resources will improve the welfare on some person or group without making someone else worse off (i.e., Pareto-efficient). One criticism of bureaucracy-based arrangements is that they often are inefficient from the standpoint that they protect fish stocks by reducing efficiency (or productivity) of fishers by increasing the level of effort needed to catch a given amount of fish. Conversely, one of the main arguments in favor of market-based systems is that tradable ITQs create a more efficient allocation of resources (Buck 1995). Accordingly, when comparing alternative institutional arrangements it is important to consider how revisions in rules affecting participants will alter their behavior and resource allocation (Ostrom et al. 1993, 113).

It is also important to consider administrative efficiency. Given variations in institutional design, it is hard to make generalizations about administrative costs. Moreover, in all four institutional arrangements, administrative efficiency may be reduced by inappropriate jurisdictional boundaries that fail to conform to biological or social conditions. In general terms, the community-based approach, with its reliance on self-regulation and social sanctions, is likely to incur lower administrative costs than other institutional arrangements. Conversely, bureaucracy- and marketbased approaches are likely to have substantially higher administrative costs due to government's involvement in administering the programs. Comanagement arrangements are designed to lower administrative costs and improve decision making by shifting administrative costs from government to industry.

Equity. Analysts should also consider whether the decision-making process is fair and results in an equitable distribution of resources, whether viewed from the perspective of horizontal or vertical equity. The IAD framework draws attention to two "equity" concepts. Fiscal equivalence holds that those who benefit from a service should bear the burden of financing it. There are important differences among the four institutional arrangements in this regard. For example, in bureaucracybased arrangements, society (i.e., the taxpayers) pays the majority of the costs associated with resource management while fishers receive the financial benefits associated with harvesting the resource. However, license fees and taxes help offset the costs to government. Conversely, under the community-based approach, resource users bear the cost of developing and enforcing rules. Under the marketbased and comanagement arrangements, there is some variation in terms of who pays these costs.

Redistribution equity is concerned with structuring program activities around differential abilities to pay. An efficient program is not necessarily a fair program. While economic efficiency dictates that resources should be allocated in a Paretoefficient manner, equity concerns may produce different resource allocations. Accordingly, there frequently are trade-offs between efficiency and equity. For example, to the extent that a bureaucracy-based arrangement relies on a standard 
set of rules applied to a similar group of fishers, everyone within this group is treated equally. Alternatively, rules can be crafted that create inequities. For example, requiring a new gear type may have a disproportional impact on small fishers compared to larger corporate boat owners. Rules can also have distributional impacts beyond fishers. For example, Buck (1995) notes that the industry consolidation necessary to increase efficiency in ITQ systems can produce job loss and other adverse impacts.

Accountability. An important principle is that governing institutions can be held accountable for their actions. There are many formal and informal accountability mechanisms, which at times will reduce efficiency or adaptability. For example, in the United States there are opportunities for public comment, open meetings laws, and various oversight mechanisms. In many developed countries, particularly those with strong democratic institutions, bureaucracy- and market-based arrangements will typically enjoy a high degree of accountability in terms of rule development and implementation, while it will vary in comanagement arrangements, based on their design. Conversely, accountability in community-based systems is more problematic and depends on the social processes used to develop rules and whether there is a mechanism for holding the community accountable to the larger society.

Adaptability. Getting the rules right takes a long time. Unless institutions have the capacity to respond to changing environments and information, institutional performance is likely to suffer (Ostrom et al. 1993, 112-116). It is hard to generalize across the four institutional arrangements because the characteristics of institutions and their local context frequently determine their adaptability. One obstacle to adaptability is that changes in rules often impact resource allocation in ways that cause various interests to resist change. Accountability mechanisms can also impede adaptability. For example, requirements for public hearings and comment can make it easier for interest groups to apply political pressure. Sometimes this pressure makes it difficult for decision makers to change rules. Conversely, too much adaptation and change in response to political pressure can create problems when changes occur before fishers adapt or analysts determine whether existing policies are working.

Policy Outcomes. Thus far, the discussion has not addressed the question of whether institutions are effective in achieving policy outcomes. This has been intentional. While many fisheries analysts are primarily concerned with whether policy outcomes have been achieved, there is no reason to suspect that one institutional arrangement will be more effective than another when it comes to maintaining fish stocks. In fact, a common flaw is equating institutional performance with policy outcomes by assuming that an institutional arrangement is performing well when the policy is achieved. Similarly, it is incorrect to assume that the failure to achieve a policy means that the institutional arrangement is flawed.

While either situation can be true, institutional performance and policy outcomes are not necessarily related. There can be a poorly performing institutional arrangement when viewed in terms of transaction costs, efficiency, equity, accountability, adaptability, or some other criterion. Yet it could be quite effective at maintaining fish stocks at desired levels because the underlying rules governing fisher behavior are sufficient to maintain sustainable fish stocks. In this situation, the analyst might be satisfied with the policy outcome, but it is arrived at through a poorly performing institutional arrangement. 
An institutional arrangement can also perform well, but nevertheless the rules restricting fishing behavior fail to prevent a fishery collapse. One might argue that the ITQ system used to manage New Zealand Orange Roughy promoted efficiency, had acceptable administrative costs, was equitable, maintained accountability, and was adaptable. However, Mace (1993) argues that because the underlying TAC setting was flawed and based on inaccurate scientific information, the institutional arrangement led to drastic stock reductions. In this case, the analyst may be pleased with the arrangement's performance, but it produced an unsatisfactory outcome.

Of course, the ideal situation is to have well-performing institutional arrangements where the underlying restrictions on fishing behavior are sufficient to maintain sustainable fish stocks. Conversely, the worse-case scenario is the poorly performing institutional arrangement that decimates a fishery in short order. Thus, analysts should remember that while policy outputs and outcomes are often affected by institutional design and performance, they are not always the product of institutional performance.

\section{Summary and Conclusions}

Fisheries analysts would be wise to recognize that no institutional arrangement is likely to be effective in all circumstances. Effective service delivery, whether it involves child support or fisheries management, requires much more than designing some theoretically optimal policy. It raises institutional, social, and moral issues that must be clarified through deliberation. Ultimately, the selection of policies and the institutional arrangements used to implement them is a political decision (Majone $1989,143)$. The job of the policy analyst is to clarify and define problems and then help decision makers identify appropriate goals, objectives, and values to achieve. This requires understanding how a program works, who benefits and loses, how it changes incentives, whether the program likely to accomplish what was intended, and how it can be improved or discontinued (Majone 1989, 167).

Sound policy analysis must also remain focused on trying to determine which institutional arrangement will perform best in a particular setting. Analysts should consider important contextual factors affecting institutional design and examine the full range of transaction costs that influence institutional performance. Given the multiple and competing policy objectives that underlie fisheries management, it is important to use a various criteria to assess overall institutional performance and understand the trade-offs that exist between them. When analyzing institutional arrangements, it is also important for analysts to avoid the common pitfalls that produce faulty advice for decision makers. Moreover, institutional arrangements and the rules that comprise them can be extremely complex. Accordingly, it is important for analysts to be disciplined in their approach to institutional analysis. The IAD framework provides a useful tool for guiding institutional analysis.

\section{Note}

1. Charles (1992) identified these as the conservation (which we discuss as bureaucracybased), rationalization (which we discuss as market-based), and social community (which we discuss as community-based) paradigms. 


\section{References}

Acheson, J. M. 1988. The Lobster gangs of Maine. Hanover, NH: University Press of New England.

Bozeman, B. 1993. Theory, "wisdom," and the character of knowledge in public management: A critical view of the theory-practice linkage. In Public management: The state of the art, ed. B. Bozeman, 27-39. San Francisco, CA: Jossey-Bass.

Buck, E. H. 1995. Individual tradable quotas in fishery management. Washington, DC: Congressional Research Service.

Charles, A. T. 1992. Fisheries conflict: A unified framework. Mar. Policy 16(September): 379-93.

Clark, I. P. 1993. Individual transferable quotas: The New Zealand experience. Mar. Policy 17(5):340-352.

Cole, D. H. and P. Z. Grossman. 2002. The meaning or property rights: Law versus economics? J. Land Econ. 78(3):317-330.

Copes, P. 1996. Social impacts of fisheries management regimes based on individual quotas. Simon Fraser University Discussion Paper Series 96-2. Burnaby, Canada: Institute of Fisheries Analysis, Simon Fraser University.

Crawford, S. E. S. and E. Ostrom. 1995. A grammar of institutions. Am. Polit. Sci. Rev. 89(3):582-600.

Davis, A. and C. Bailey. 1996. Common in custom, uncommon in advantage: Common property, local elite, and alternative approaches to fisheries management. Society Nat. Resources 9:251-265.

Dewees, C. M. 1989. Assessment of the implementation of individual transferable quotas in New Zealand's inshore fishery. North Am. J. Fish. Manage. 9(2):131-139.

Grafton, R. Q. 1996. Experiences with individual transferable quotas: An overview. Can. J. Econ. 24(special issue):S135-S138.

Halliday, R. G. and A. T. Pinhorn. 1997. Policy frameworks. In Northwest Atlantic groundfish: Perspectives on a fishery collapse, ed. J. Boreman, B. S. Nakashima, J. A. Wilson, and R. L. Kendall, 95-109. Bethesda, MD: American Fisheries Society.

Hennessey, T. and M. Healey. 2000. Ludwig's ratchet and the collapse of New England groundfish stocks. Coastal Manage. 28(3):187-213.

Imperial, M. T. 1999. Analyzing institutional arrangements for ecosystem-based management: The institutional analysis and development framework. Environ. Manage. 24:449-465.

Kiser, L. and E. Ostrom. 1982. The three worlds of action: A metatheoretical synthesis of institutional approaches. In Strategies for political inquiry, ed. E. Ostrom, 179-222. Beverly Hills, CA: Sage.

Kneese, A. V. and C. L. Schultze. 1975. Pollution, prices, and public policy. Washington, DC: The Brookings Institution.

Komesar, N. K. 1994. Imperfect alternatives: Choosing institutions in law economics, and public policy. Chicago, IL: University of Chicago Press.

Larkin, P. A. 1977. An epitaph for the concept of maximum sustained yield. Trans. Am. Fish. Soci. 106:1-11.

Leal, D. R. 2002. Fencing the fishery: A primer on ending the race for fish. Bozeman, MT: Political Economy Research Center.

Mace, P. M. 1993. Will private owners practice prudent resource management? Fisheries 18(9):29-31.

Majone, G. 1989. Evidence, argument, \& persuasion in the policy process. New Haven, CT: Yale University Press.

McCay, B. J. 1993. Management regimes. Beijer Discussion Paper Series number 38. Beijer International Institute of Economics.

McCay, B. J. and S. Jentoft. 1996. From the bottom up: Participatory issues in fisheries management. Society Nat. Resources 9:237-250. 
Myers, R. A. and B. Worm. 2003. Rapid worldwide depletion of predatory fish communities. Nature 423:280-283.

Olson, M. 1965. The logic of collective action: Public goods and the theory of groups. Cambridge, MA: Harvard University Press.

Ostrom, E. 1986. An agenda for the study of institutions. Public Choice 48(1):3-25.

Ostrom, E. 1990. Governing the commons: The evolution of institutions for collective action. New York: Cambridge University Press.

Ostrom, E. 1999. Institutional rational choice: An assessment of the institutional analysis and development framework. In Theories of the policy process, ed. P. A. Sabatier, 35-71. Boulder, CO: Westview Press.

Ostrom, E., R. Gardner, and J. Walker. 1994. Rules, games, \& common-pool resources. Ann Arbor: University of Michigan Press.

Ostrom, E. and E. Schlager. 1996. The formation of property rights. In Rights to nature: Ecological, economic, cultural, and political principles of institutions for the environment, ed. S. Hanna and A. Jansson, 127-156. Washington, DC: Island Press.

Ostrom, E., L. Schroeder, and S. Wynne. 1993. Institutional incentives and sustainable development: Infrastructure policies in perspective. Boulder, CO: Westview Press.

Palsson, G. and A. Helgason. 1996. Figuring fish and measuring men: The individual tradable quota system in the Icelandic cod industry. Ocean Coastal Manage. 28:117-146.

Rose, C. M. 2002. Common property, regulatory property, and environmental protection: Comparing community-based management to tradable environmental allowances. In The drama of the commons, ed. E. Ostrom, T. Dietz, N. Dolsak, P. C. Stern, S. Stovich, and E. U. Weber, 233-257. Washington, DC: National Academy Press.

Rose, R. 1993. Lesson-drawing in public policy: A guide to learning across time and space. Chatham, NJ: Chatham House.

Smith, S., S. Jacob, M. Jepson, and G. Israel. 2003. After the Florida net ban: The impacts on commercial fishing families. Society Nat. Resources 16(1):39-60.

Squires, D., J. Kirkley, and C. A. Tisdell. 1995. Individual transferable quotas as a fisheries management tool. Rev. Fish. Sci. 3(2):141-169.

Wilen, J. E. 1995. U.S. fishery regulation policy: Lessons for Peru. In Managing fisheries resources: Proceedings of a symposium co-sponsored by the World Bank and Peruvian Ministry of Fisheries held in Lima Peru, June 1992, ed. E. A. Loayza, 39-43. Washington, DC: World Bank.

Williamson, O. E. 1985. The economic institutions of capitalism: Firms, markets, relational contracting. New York: Free Press.

Yandle, T. 2003. The challenge of building successful stakeholder groups: New Zealand's experience in developing a co-management regime. Mar. Policy 27(2):179-192.

Yandle, T. 2004. Developing a co-management approach in New Zealand fisheries. In Evolving property rights in marine fisheries, ed. D. R. Leal, 213-238. Lanham, MD: Rowman \& Littlefield. 